\title{
Weight Gain in Epileptic Patients During Treatment with Valproic Acid: a Retrospective Study
}

\author{
Céline L. Corman, Nathalie M. Leung and Alan H. Guberman
}

\begin{abstract}
Background: Weight gain has been recognized as a common adverse effect of valproic acid (VPA) that leads to discontinuation in some patients but its incidence and correlates have been rarely studied. Methods: We have analyzed the records retrospectively and interviewed 70 adult patients attending an epilepsy clinic on VPA mono- or polytherapy followed over a median of 27 months (range 3-189), as well as 20 patients on carbamazepine (CBZ) monotherapy. Patients were divided into non-weight gainers $(<5 \%$ baseline body weight), mild-moderate weight gainers (5-10\% body weight) and marked weight gainers ( $>10 \%$ body weight). The following variables were statistically analyzed to determine their relationship to weight gain: gender, age, body mass index, drug dose, personal or family history of obesity and monotherapy versus polytherapy. Results: Seventy-one percent of the VPA group were weight gainers versus $43 \%$ in the CBZ group. A weight gain of more than $4 \mathrm{~kg}$ in $70 \%$ of the VPA group was observed. The weight gain was often sustained and frequently socially significant to the patients. Patients below or within normal range body mass index prior to the start of VPA experienced the most severe percentage weight gain. From the structured patient interviews, patients with no personal history of weight problems experienced the greatest initial weight increase. Conclusion: Strategies should be devised to help patients avoid weight gain when starting on VPA, especially if they are not already overweight.
\end{abstract}

\begin{abstract}
RÉSUMÉ: Gain de poids chez les patients épileptiques traités par l'acide valproïque: étude rétrospective. Introduction: Il est connu que le gain de poids est une effet secondaire fréquent du traitement par l'acide valproïque (AVP), ce qui entraîne la cessation de la médication chez certains patients. Cependant, on a rarement étudié son incidence et les éléments qui lui sont corrélés. Méthodes: Nous avons analysé rétrospectivement les dossiers de 90 patients adultes d'une clinique d'épilepsie et nous les avons soumis à une entrevue. Soixante-dix de ces patients étaient sous AVP en mono ou polythérapie et 20 étaient sous carbamazépine (CBZ) en monothérapie, et ils avaient été suivis sur une période médiane de 27 mois ( 3 à 189 mois). Les patients ont été regroupés selon leur gain de poids: aucun gain de poids ( $<5 \%$ du poids initial), gain de poids léger à modéré (5-10\%) et gain de poids marqué (> 10\%). Les variables suivantes ont servi à l'analyse statistique afin de déterminer leur relation avec le gain de poids: le sexe, l'âge, l'indice de masse corporelle (IMC), la posologie, l'histoire familiale ou personnelle d'obésité et la monothérapie versus la polythérapie. Résultats: Soixante-et-un pourcent du groupe recevant l'AVP avait pris du poids versus $43 \%$ du groupe CBZ. On a observé un gain de plus de $4 \mathrm{~kg}$ chez $70 \%$ du groupe AVP. Le gain de poids était souvent persistant et significatif socialement pour les patients. Les patients qui avaient un IMC sous ou dans les limites de la normale avant le début du traitement ont présenté le pourcentage de gain de poids le plus élevé. Les entrevues structurées ont révélé que les patients qui n'avaient pas d'histoire personnelle de problèmes de poids ont présenté le plus grand gain de poids initialement. Conclusion: Des stratégies devraient être développées pour aider les patients à maintenir leur poids stable quand ils commencent à prendre l'AVP, surtout s'ils n'ont pas déjà un excès de poids.
\end{abstract}

Can. J. Neurol. Sci. 1997; 24: 240-244

Since the first report on the anticonvulsant properties of valproic acid (VPA) by Meunier et al. in 1963, ${ }^{1}$ the use of the drug in the treatment of epilepsy has expanded considerably. Its broad spectrum of anticonvulsant activity, and the fact that it is relatively free of side effects compared to most of the standard antiepileptic drugs, have made VPA the drug of choice for a wide variety of seizure types. ${ }^{2.3}$ However, with growing experience, there has also been increasing awareness of some of the unwanted side effects of VPA, including weight gain. This weight gain has been implicated in drug therapy withdrawal or

From the Department of Pharmacy and Division of Neurology (N.M.L., A.H.G.), Ottawa General Hospital, Ottawa.

RECEIVED JULY 23, 1996. ACCEPTED IN FINAL FORM MARCH 21, 1997.

Reprint requests to: Alan Guberman, Division of Neurology, Ottawa General Hospital, 501 Smyth Road, Ottawa, Ontario, Canada K1H 8 L6 
poor compliance in some patients and may also pose a health risk. $^{4-7}$ Yet only a few studies have attempted to address the incidence of weight gain with VPA and its correlation with specific patient and drug factors (e.g., dosing regimen, serum drug levels, other side-effects). ${ }^{8,9}$ The objectives of this study were to determine the frequency and degree of weight gain associated with the use of VPA in patients attending an epilepsy clinic and factors that may predispose these patients to developing weight gain during VPA therapy.

\section{MethodS}

Seventy adult patients, between the ages of 17 and 68 years, on VPA, meeting evaluation criteria, were selected from an epilepsy clinic population of 600 patients. Patients on monotherapy (47) and polytherapy (23) were included. Information on body weight, VPA dosage and serum concentration, concurrent antiepileptic(s) and dosage and serum concentration, other adverse effects of VPA and the degree of seizure control was obtained through a retrospective chart review. Each time a patient was clinically reviewed, the weight was measured and recorded.

To qualify for the study, patients had to have been on VPA for at least 3 months and their weight measured within 3 months prior to starting the medication. Patients were excluded if they had complicating medical illnesses, or were noncompliant with their medication, or were concomitantly taking clobazam which can alter weight $(n=12) .{ }^{10}$ Patients whose charts did not contain sufficient information for analysis were excluded $(n=59)$.

Charts reviewed covered the period from October 1978 to August 1994 with a median follow-up time of 27 months (range 3-189 months).

Structured telephone interviews were carried out with 55 of the 70 patients, or their caretakers in the case of mentally handicapped patients. Questions dealt with personal history of weight gain prior to initiation of VPA (variables included were: overweight as a child, periods of weight gain in life, weight gain of more than $12 \mathrm{~kg}$ during pregnancies and obesity before treatment); family history of obesity (variables included were: father ever overweight, mother ever overweight, siblings ever overweight, children ever overweight); weight pattern during VPA therapy; dietary habits and appetite changes while on VPA, adverse effects and life effects (such as social and self-esteem). Height obtained from the interviews was utilized to calculate Body Mass Index (BMI) of each patient prior to the start of VPA treatment. BMI was used in this study to measure obesity because it is simple, convenient and correlates well with body density and skin fold measures. ${ }^{11,12}$ BMI was calculated as weight in kilograms divided by the square of height in metres. A value exceeding $25 \mathrm{~kg} / \mathrm{m}^{2}$ was considered overweight.

The patients were classified as non-weight gainers $(<5 \%$ baseline body weight); mild-moderate weight gainers (5-10\% baseline body weight) and marked weight gainers ( $>10 \%$ baseline body weight). Rate of weight gain was separated into 3 groups: lost more than $3 \mathrm{~kg}$ in the first 3 months after starting VPA, lost or gained no more than $3 \mathrm{~kg}$ in the first 3 months and gained more than $3 \mathrm{~kg}$ in the first 3 months.

Twenty-one patients on carbamazepine (CBZ) monotherapy were selected as controls for a similar analysis.

All data analyses were performed using the chi-square test with SAS software (SAS Institute Inc., 1989). An initial paired $t$ test was used for baseline weight versus maximum weight gain while on VPA therapy and $t$ tests were utilized for women versus men for initial starting dose $(\mathrm{mg} / \mathrm{kg})$ and for dose $(\mathrm{mg} / \mathrm{kg})$ at maximum weight gain. A probability value of $<0.05$ was chosen as statistically significant.

\section{Results}

Our patient characteristics and distribution of weight gain during VPA therapy are shown in Table 1. There was a statistically significant difference for baseline weight versus maximum weight gain while on VPA therapy $(\mathrm{p}=0.001)$. Overall, there was a statistically significant difference between the percentage of patients who gained weight ( $>5 \%$ of baseline body weight) and the percentage remaining weight stable during VPA therapy $(p=0.001)$. In the VPA group $24 \%$ of patients were mild-moderate weight gainers and $47 \%$ were marked weight gainers. By contrast, 6 patients $(28 \%)$ on CBZ monotherapy were mildmoderate weight gainers and 3 patients $(14 \%)$ were marked weight gainers ( $\mathrm{p}=0.016$ for weight gain versus non-weight gain between CBZ and VPA) (Figure 1).

On VPA, in the mild-moderate weight gain group, the mean weight gain was $4.9 \mathrm{~kg} \pm 0.92 \mathrm{~kg}$ (range $3.1-6.5 \mathrm{~kg}$ ) and in the marked weight gain group the mean weight gain was $11.4 \mathrm{~kg} \pm$ $4.9 \mathrm{~kg}$ (range $5.5-30.1 \mathrm{~kg}$ ). The mean overall weight change in the 70 patients was $6.9 \mathrm{~kg} \pm 5.8 \mathrm{~kg}$ (range $-4.0-30.1 \mathrm{~kg}$ ). The highest maximum weight gain observed was $54 \%$ of initial body weight for VPA. This corresponded to a $30 \mathrm{~kg}$ weight gain over a period of 15 months. Her BMI prior to the start of VPA therapy was within the normal range (i.e., BMI < 25).

Five patients, all in the $>10 \%$ weight gain group, stopped taking VPA because of weight gain. Four of the five patients lost significant weight after stopping VPA. Two of the five patients had achieved complete seizure control whereas the other three had experienced poor to moderate seizure control.

There were no statistically significant differences between women and men with regard to initial starting dose $(\mathrm{mg} / \mathrm{kg})$ of VPA or VPA dose $(\mathrm{mg} / \mathrm{kg})$ at maximum weight gain.

There were no statistically significant differences between $>10 \%$ weight gainers and $\leq 10 \%$ weight gainers with regard to gender (Figure 2 ), age, initial maintenance dose $(\leq 1000 \mathrm{mg} /$ day

Table 1: Comparison of Three Weight-change Groups on VPA.

\begin{tabular}{lccc}
\hline & $<\mathbf{5 \%}$ wt. gain & $\mathbf{5 - 1 0 \%}$ wt. gain & $>\mathbf{1 0 \%}$ wt. gain \\
\hline Females (F) & 13 & 12 & 27 \\
\hline Males (M) & 7 & 5 & 6 \\
\hline$\&$ of total & $29 \%$ & $24 \%$ & $47 \%$ \\
\hline $\begin{array}{l}\text { Age (yr) F\&M } \\
\text { Pre-treatment }\end{array}$ & $34.7(19.1-65.8)$ & $36.1(17.7-68.5)$ & $31.2(17.2-63.8)$ \\
\begin{tabular}{l} 
overweight ${ }^{\text {a,b }}$ \\
\hline $\begin{array}{l}\text { Duration of } \\
\text { therapy (mo) }\end{array}$
\end{tabular} & $26(3-83)$ & $66.7 \%$ & $23.1 \%$ \\
\hline $\begin{array}{l}\text { Mean dosage } \\
\text { (mg/day) }\end{array}$ & $1309(500-2333)$ & $1160(625-2375)$ & $1253(484-2500)$ \\
\hline
\end{tabular}

a: based on Body Mass Index (BMI) $>25$

b: $n=54$ 




Figure 1: Maximum weight gain in VPA and CBZ groups.

versus $>1000 \mathrm{mg} /$ day), dose at maximum weight gain, monoversus polytherapy and family history of weight problems. However, from the structured patient interviews, patients below or within normal range BMI prior to the start of VPA experienced the most severe relative weight gain $(>10 \%)(p=0.005)$ and it appears that patients with no personal history of obesity initially gained the most weight $(\mathrm{p}=0.035)$. Time to maximum weight gain was plotted for both weight gain groups (Figure 3). Maximum weight gain was recorded at the last follow-up visit for 11 of 17 patients in the mild to moderate weight gain group (i.e., 6 patients had reached their maximum weight gain prior to last follow-up appointment) and for 17 of 33 patients in the moderate to severe weight gain group (i.e., 16 patients had reached their maximum weight gain prior to the last follow-up visit).

The weight loss observed, after reaching maximum weight gain, in the mild to moderate weight gain group was $6.7 \mathrm{~kg} \pm$ $8.3 \mathrm{~kg}$ (range $0.7-22.9 \mathrm{~kg}$ ) over a mean period of $10.7 \pm 5$ months (range 4-16 months). Three out of the 6 patients, who achieved their maximum weight gain before the last follow-up visit, returned to baseline weight or below after achieving maximum weight gain while on VPA. The weight loss observed, after reaching maximum weight gain, in the marked weight gain group was $3.5 \mathrm{~kg} \pm 4.7 \mathrm{~kg}$ (range $0-18.7 \mathrm{~kg}$ ) over a mean period of $10 \pm 8.2$ months (range 2-34 months). However none of the 16 patients in this group returned to or below baseline weight.

Forty-nine percent $(n=27)$ of our interviewed patients reported increased appetite of which $63 \%$ (17/27) were in the marked weight gain group. We also noted that $20 \%$ of our interviewed patients reported increased thirst or increased intake of beverages.

Measures reported by some of our patients to lose or control their weight included exercise, diet, advice of a dietician, join- ing Weight-Watchers or Nutri-System, seeking advice from a family physician, psychologist or psychiatrist and taking medication to lose weight. According to our patients, none of those measures were effective in reducing their weight. It has been previously noted that the weight gained during VPA therapy was difficult to reverse by dietary restrictions. ${ }^{9,14}$ Weight gain may affect compliance or lead to discontinuation of therapy as occurred in $9 \%$ of our 55 patients.

Five patients actually lost weight. The weight loss observed ranged from 1-16.2 kg over 2-64 months. Poor appetite was the main reported reason for the weight loss.

\section{Discussion}

Weight gain has frequently been reported in clinical trials (in children and adults) with VPA, although the quoted incidence of the side effect has varied from $7.5-59 \%$ in adult studies. $2,4-6,13-15$ Our study demonstrates a $47 \%$ incidence of gain of more than $10 \%$ of baseline body weight and a $24 \%$ incidence of $5-10 \%$ weight gain after the start of VPA therapy in adults. Dinesen et al. reported a $57 \%$ incidence of weight increase of more than 4 kg. ${ }^{9}$ We observed a weight gain of more than $4 \mathrm{~kg}$ in $70 \%$ of our patients. Dam and Gram noted a weight gain of $4.3 \mathrm{~kg}$ or more in $73 \%$ of their patients. A mean weight gain of $4.3 \mathrm{~kg}$ in men and $4.9 \mathrm{~kg}$ in women was observed. ${ }^{8}$ Of note in our study is that $54 \%$ of the patients who gained $>5 \%$ body weight reached their maximum weight gain at the last follow-up visit and could conceivably have continued to gain. Weight continued to rise up to 4 years or more on the drug in some patients. This was also observed by Isojarvi et al. in their retrospective analysis of 22 valproate-treated women, 11 of whom had significant weight gain. The authors stated that many of their subjects had experienced a weight gain that was progressive with a maximum increase in 1 subject from 57.5 to $106.5 \mathrm{~kg}$ during 9 years of 


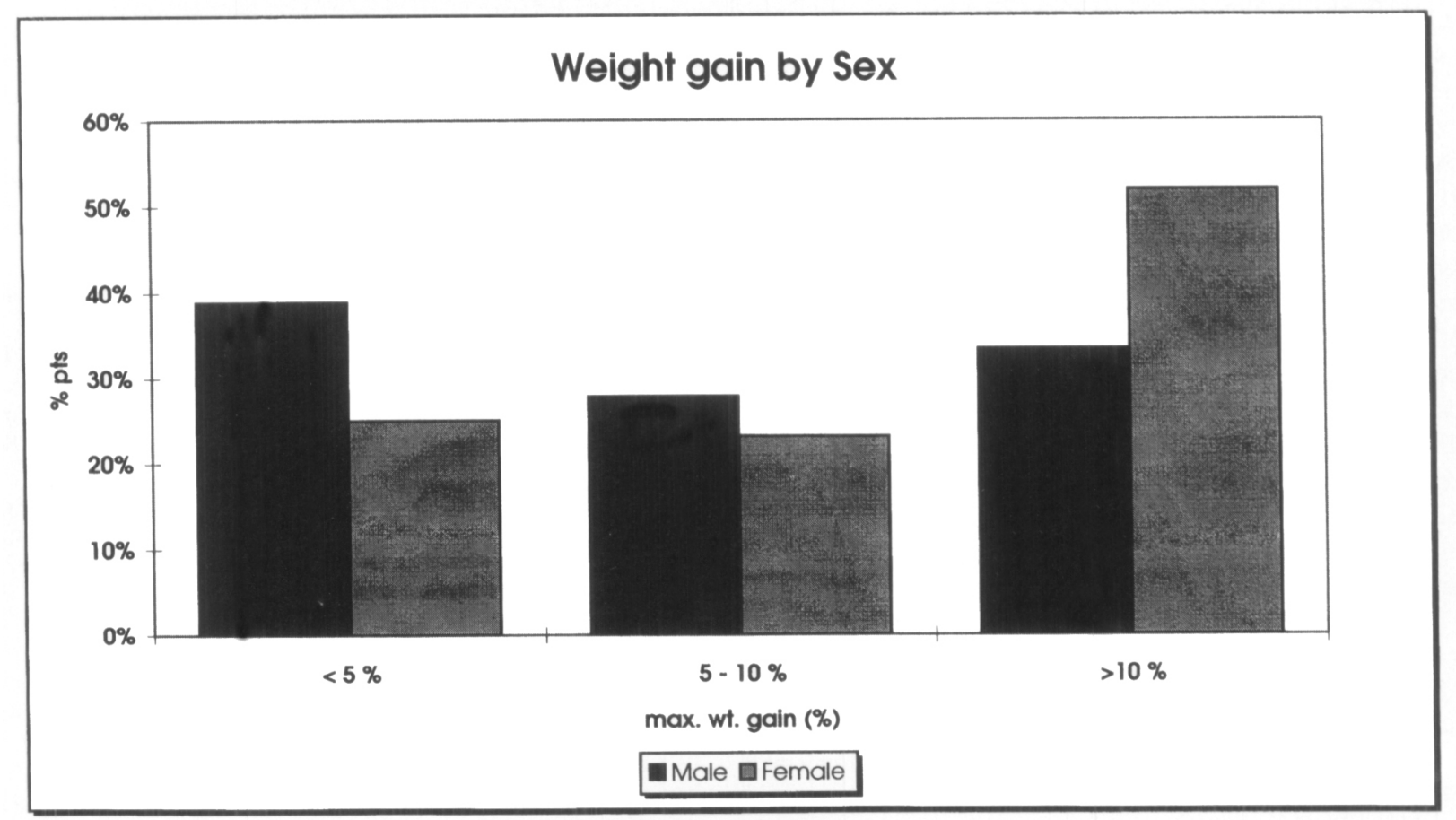

Figure 2: Weight gain by sex.

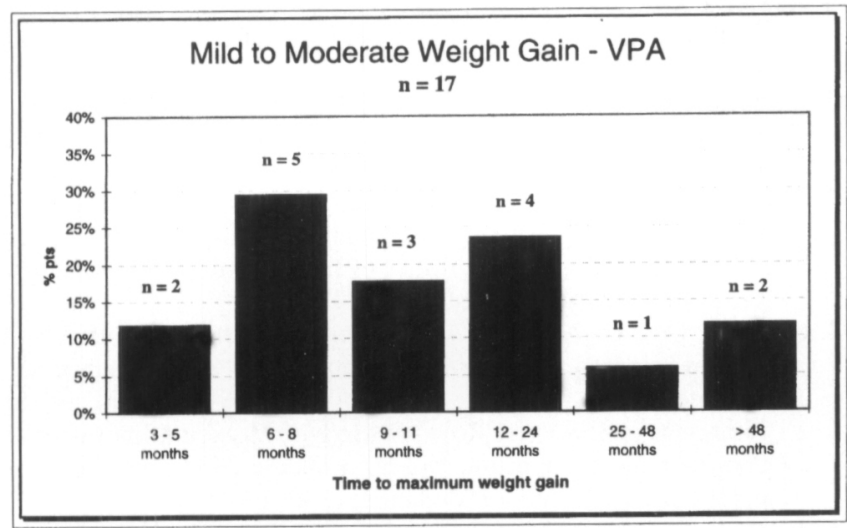

Maximum weight gain was recorded at the last follow-up visit for 11 out of 17 patients.

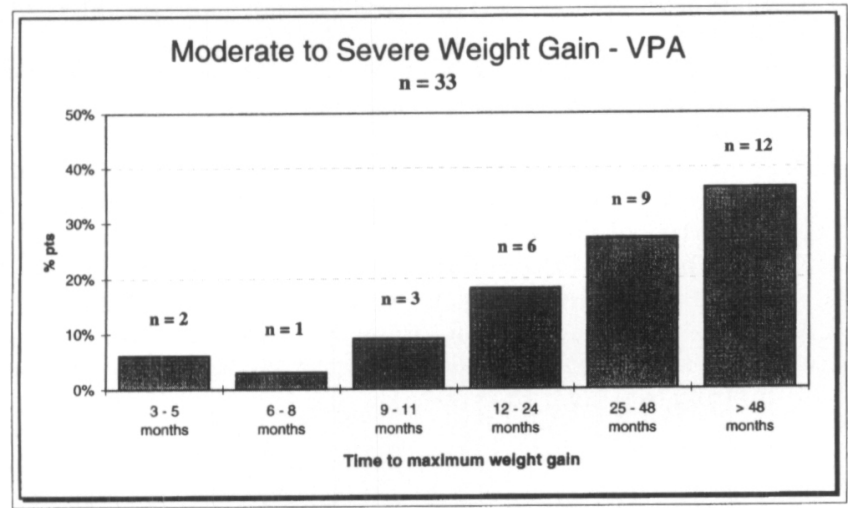

Maximum weight gain was recorded at the last follow-up visht for 17 out of 33 patients.

Figure 3. therapy. ${ }^{16}$ They also reported that the weight gain in women taking VPA for epilepsy was associated with hyperinsulinemia and low serum insulin-like growth factor-binding protein 1 (IGFBP1) which could lead to hyperandrogenism and polycystic ovaries. ${ }^{16}$

Weight gain was associated more frequently with VPA than with CBZ ( $47 \%$ versus $14 \%$ in the $>10 \%$ weight gain group). Mattson and colleagues observed a similar trend in that a large weight gain (defined as a gain of $5.5 \mathrm{~kg}$ or more) was seen in $20 \%$ of patients taking VPA versus $8 \%$ of patients taking CBZ $(\mathrm{p}<0.001){ }^{2}$ Davidson and co-workers reported weight gain as the most common non-neurological adverse event in $13 \%(20$ patients) of patients treated with VPA but only $1 \%$ (2 patients) treated with CBZ. 5,13

The cause of weight gain with valproic acid remains unknown. ${ }^{7}$ Several mechanisms have been postulated, including increased appetite and food intake, $, 17,18$ increased thirst and intake of energy-rich beverages, ${ }^{9,17}$ direct effect of VPA or a metabolite on the hypothalamus, ${ }^{18}$ decreased capacity for luxury consumption or facultative thermogenesis (minor temperature changes in the hypothalamus may explain increased appetite),, 17.18 and impaired metabolism of fatty acids. ${ }^{17}$ Recently Vorum and associates proposed a theory encompassing several of the above postulated mechanisms based on their study showing that VPA competed with palmitate for binding to human serum albumin, resulting in increased availability of fatty acids. ${ }^{19}$ The increase in amount of fat available for deposition in adipose tissue is compounded by the fact that VPA interferes with fatty acid metabolism, namely $\boldsymbol{B}$-oxidation, by causing a deficiency in carnitine. Decreased B-oxidation of fatty acids may also explain the need for other "fuels" such as glucose, which is also affected by VPA since the drug has a concentration-dependent inhibitory effect on gluconeogenesis from 
lactate, glycerol, and alanine. The resulting hypoglycemia would stimulate appetite and increased food intake which, coupled to the increase in fatty acid availability, causes obesity. ${ }^{19}$ Isojarvi et al. have suggested hyperinsulinemia, due to decreased insulin binding, as a mechanism. ${ }^{16}$

Forty-nine percent of our interviewed patients reported increased appetite. Dinesen et al. found $46 \%$ of their patients experienced increased appetite during VPA treatment including both weight gainers and weight stable patients. ${ }^{9}$ We noted that $20 \%$ of the interviewed patients reported increased thirst or increased intake of beverages while Dinesen et al. noted $33 \%$ of their patients reported a similar occurrence. ${ }^{9}$

Unlike Dam and $\mathrm{Gram}^{8}$ we did not show a relationship between the dose of VPA and weight gain. Our average dosage was $1226 \mathrm{mg}$ for women and $1251 \mathrm{mg}$ for men which was similar to their $1200 \mathrm{mg}$ for women and $1000 \mathrm{mg}$ for men. Laljee and Parsonage noted a slightly greater weight gain in women (mean $14.5 \mathrm{~kg}$ in women versus $12.44 \mathrm{~kg}$ in men). ${ }^{4}$ We noted a similar trend: mean weight gain of $11.6 \mathrm{~kg}$ for women versus $8.8 \mathrm{~kg}$ for men, which did not achieve statistical significance in this small group.

The time to maximum weight gain may have been influenced by appointment intervals which may have distorted the results. Patients with less severe seizure disorders and longer travel distance may have had their weight measured less frequently, therefore biassing the results.

We recognize that in some patients, an explanation for weight gain may have been related to discontinuation of previous medication when VPA was instituted. There was no consistent pattern in this regard and weight loss is not a feature of most antiepileptic drugs.

Patients starting on VPA should be warned of possible weight gain, especially if they are not overweight to begin with. Strategies, such as optimizing diet and establishing an exercise routine, should be devised to help patients avoid weight gain when starting on VPA, but realizing that these are often ineffective. It may also be prudent to avoid, where possible, combinations of VPA with other antiepileptic drugs (such as carbamazepine, gabapentin and vigabatrin) which can lead to weight gain.

\section{ACKNOWLEDGEMENTS}

We thank Mr. J. Corman for preparing Figures 1-3 and Ms. E.A. Yetisir for her assistance with statistical analysis.

\section{REFERENCES}

1. Meunier H, Carraz G, Meunier V, Eymard M. Propriétés pharmacodynamiques de l'acide n-propylacétique. Thérapie 1963; 18: 435-438.

2. Mattson RH, Cramer JA, Collins JF, et al. A comparison of valproate with carbamazepine for the treatment of complex partial seizures and secondarily generalized tonic-clonic seizures in adults. N Engl J Med 1992; 327: 765-771.
3. Davis R, Peters DH, McTavish D. Valproic acid - a reappraisal of its pharmacological properties and clinical efficacy in epilepsy. Drugs 1994; 47: 332-372.

4. Laljee HCK, Parsonage MJ. Unwanted effects of sodium valproate in the treatment of adult patients with epilepsy. In: Parsonage MJ, Caldwell ADS, eds. The Place of Sodium Valproate in the Treatment of Epilepsy: Royal Society of Medicine International Congress and Symposium No. 30. London: Academic Press Inc and the Royal Society of Medicine, 1980: 141-158.

5. Davidson DLW. The adult EPITEG trial: a comparative multicentre clinical trial of sodium valproate and carbamazepine in adult onset epilepsy. Part 2; adverse effects. In: Chadwick DW, ed. Proceedings of the Fourth International Symposium on Sodium Valproate and Epilepsy, International Congress and Symposium Series No. 152. London: Royal Society of Medicine Services, 1989: 114-121.

6. Spitz MC, Deasy DN. Conversion to valproate monotherapy in nonretarded adults with primary generalized tonic-clonic seizures. J Epilepsy 1991; 4: 33-38.

7. Pijl H, Meinders AE. Bodyweight change as an adverse effect of drug treatment. Mech Management. Drug Safety 1996; 14: 329342.

8. Dam M, Gram L. Weight changes in epileptic patients treated with valproate. In: Pedersen B, Orum H, eds. Valproate in the Treatment of Seizures: meeting of the Danish Epilepsy Society. Copenhagen: Danish Epilepsy Society, 1981: 83-85.

9. Dinesen H, Gram L, Andersen, Dam M. Weight gain during treatment with valproate. Acta Neurol Scand 1984; 69: 65-69.

10. Ananth J, Van Den Steen N. Clobazam in the treatment of anxiety neurosis: a double-blind study. Curr Ther Res 1979; 26: 119-126.

11. Reader BA, Angel A, Ledoux M, et al. Obesity and its relation to cardiovascular disease risk factors in Canadian adults. Can Med Assoc J 1992; 146 (11): 2009-2019.

12. Canadian Guidelines for Healthy Weights: promoting healthy weights (discussion paper), Health and Welfare Canada, Health Services and Promotion Branch, Ottawa, 1988.

13. Price DJE. The advantages of sodium valproate in neurosurgical practice. I $n$ : Legg HJ, ed. Clinical and Pharmacological Aspects of Sodium Valproate (Epilim) in the Treatment of Epilepsy. Kent, England: MCS Consultants, 1975: $44-49$

14. Clark JE, Covanis A, Gupta AK, Jeavons PM. Unwanted effects of sodium valproate in children and adolescents. In: Parsonage MJ, Caldwell ADS, eds. The Place of Sodium Valproate in the Treatment of Epilepsy: Royal Society of Medicine International Congress and Symposium No. 30. London: Academic Press Inc and the Royal Society of Medicine, 1980: 133-139.

15. Richens A, Davidson DLW, Cartlidge NEF, et al. A multicentre comparative trial of sodium valproate and carbamazepine in adult onset epilepsy. J Neurol Neurosurg Psychiatry 1994; 57: 682-687.

16. Isojarvi JIT, Laatikainen TJ, Knip M, et al. Obesity and endocrine disorders in women taking valproate for epilepsy. Ann Neurol 1996; 39: 579-584.

17. Breum L, Astrup A, Gram L, et al. Metabolic changes during treatment with valproate in humans: implication for untoward weight gain. Metabolism 1992; 41: 666-670.

18. Egger J, Brett EM. Effects of sodium valproate in 100 children with special reference to weight. Br Med J 1981; 283: 577-580.

19. Vorum H, Gram L, Honoré B. Valproate and palmitate binding to serum albumin in valproate-treated patients. Relation to obesity. Epilepsy Res 1993; 16: 55-64. 